\title{
Experimental Myocardial Infarction
}

\author{
VIII. CHRONOTROPIC AUGMENTATION OF CARDIAC \\ FUNCTION IN LEFT VENTRICULAR FAILURE OF \\ ACUTE AND HEALING STAGES IN INTACT \\ CONSCIOUS DOGS
}

\author{
Raj Kumar, Julio Joison, David P. Gilmour, Farouk A. Molokhia, \\ C. A. S. Pegg, and William B. Hood, Jr. \\ From the Thorndike Memorial Laboratory, Harvard Medical Unit, and Sears \\ Surgical Laboratory, Harvard Surgical Service, Boston City Hospital, and \\ the Departments of Medicine and Surgery, Harvard Medical School, \\ Boston, Massachusetts 02130
}

A B S T R A C T The hemodynamic effects of tachycardia induced by atrial pacing were investigated in left ventricular failure of acute and healing experimental myocardial infarction in 20 intact, conscious dogs. Myocardial infarction was produced by gradual inflation of a balloon cuff device implanted around the left anterior descending coronary artery 10-15 days prior to the study. $1 \mathrm{hr}$ after acute myocardial infarction, atrial pacing at a rate of 180 beats/min decreased left ventricular end-diastolic pressure from 19 to $8 \mathrm{~mm} \mathrm{Hg}$ and left atrial pressure from 17 to $12 \mathrm{~mm} \mathrm{Hg}$, without change in cardiac output. In the healing phase of myocardial infarction $1 \mathrm{wk}$ later, atrial pacing decreased left ventricular end-diastolic pressure from 17 to $9 \mathrm{~mm} \mathrm{Hg}$ and increased the cardiac output by $37 \%$. This was accompanied by evidence of peripheral vasodilation. In two dogs with healing anterior wall myocardial infarction, left ventricular failure was enhanced by partial occlusion of the circumflex coronary artery. Both the dogs developed pulmonary edema. Pacing improved left ventricular performance and relieved pulmonary edema in both animals. In six animals propranolol was given after acute infarction, and left ventricular function deteriorated further. However the pacing-induced augmentation of cardiac function was unaltered and, hence, is not mediated by sympathetics.

The results show that the spontaneous heart rate in left ventricular failure of experimental canine myo-

This work was presented in part at the 42nd Scientific Sessions of the American Heart Association, Dallas, Texas.

Received for publication 29 June 1970 and in revised form 2 September 1970. cardial infarction may be less than optimal and that maximal cardiac function may be achieved at higher heart rates.

\section{INTRODUCTION}

The effect of increasing the heart rate by pacing upon hemodynamics and myocardial contractility in the normal heart has been the subject of various investigations. In the isolated ventricle $(1,2)$, isolated mammalian cardiac muscle $(3,4)$, and canine bypass preparations (5), increase in force of contraction occurs with increasing frequency of contraction up to a certain range. In intact animals (6-9) and in man (10) with normal cardiac function, this increase in inotropy is not readily appreciated by routine hemodynamic measurements. Increases in cardiac output or marked decreases in left ventricular filling pressures are seldom noted over a wide range of cardiac rates.

In the presence of cardiac disease, the effects of increasing heart rate by pacing are less well understood. In the presence of elevated filling pressure in animals (6) or complete heart block and congestive failure in patients, increasing the cardiac rate may improve cardiac output $(11,12)$. Conversely, angina pectoris and acute left ventricular failure may be precipitated by induced tachycardia in some patients with coronary artery disease $(13,14)$. These varying effects of pacing may depend upon a critical balance of factors influencing myocardial oxygen supply and demand, including extent of coronary disease and presence of 
collaterals, and hemodynamic factors such as inotropic state and left ventricular wall stress.

In acute myocardial infarction, in which both coronary ischemia and congestive failure are present, the hemodynamic effects of pacing at rates which are faster than normal have not been explored. The present study was designed to investigate the effects of increasing cardiac rate by pacing in the presence of left ventricular failure of acute and healing myocardial infarction in dogs.

\section{METHODS}

20 mongrel dogs weighing $23.2 \pm 0.2$ (SEM) $\mathrm{kg}$ were studied. The technique of producing myocardial infarction in the intact conscious dog has been reported in detail (15-17). 10-15 days prior to the study, a thoracotomy was performed under pentobarbital anesthesia, and balloon cuff devices were placed around left anterior descending and circumflex coronary arteries. Two pacing wires were sutured within a muscular tunnel, constructed by plication of the left atrial wall. The atrial pacing wires and balloon cuff devices were exteriorized on the dorsum. In four animals a band was placed around the ascending aorta as previously described (18) to permit later testing of ventricular function curves by pressure loading of the left ventricle $(19,20)$.

After a 10-15 day postsurgical recovery period, the awake animals were studied under mild sedation with morphine sulphate $15 \mathrm{mg}$ i.m., given $1 \mathrm{hr}$ before the studies. Through femoral arterial and venous cutdowns performed under local anesthesia (lidocaine $1 \%$ ) a polyethylene catheter (1.D. 0.045 in.) was placed in the aorta under fluoroscopic control, and Cournand catheters Nos. 7-9 (100 cm in length) were placed in the pulmonary artery and left ventricle. In nine animals an additional catheter was placed retrogradely in the left atrium. Measurements were made of heart rate, cardiac output, aortic, pulmonary arterial, left atrial, and left ventricular pressures. After completion of the study, the arteriotomy was repaired. The animals were restudied in similar fashion 6-8 days later during the healing phase of myocardial infarction.

Experimental design. Effects of atrial pacing at a rate of approximately 180 beats/min were studied under the following conditions.

(a) Eight animals were studied before and $1 \mathrm{hr}$ after myocardial infarction produced by occluding the left anterior descending coronary artery and again 1 wk later.

(b) In six animals studies were carried out as in group $a$, and in addition, after administration of propranolol in doses of $0.4 \mathrm{mg} / \mathrm{kg}$ given $80 \mathrm{~min}$ after acute myocardial infarction. This was done for the following reasons: to study the efficacy of pacing when left ventricular failure due to myocardial infarction was further enhanced by propranolol; and to study the possible contribution of sympathetic stimulation in pacing-induced augmentation of cardiac function.

(c) In two animals with healing anterior wall myocardial infarction ( 7 days after acute myocardial infarction), the circumflex coronary artery was partially constricted but not totally occluded. This resulted in severe left ventricular failure, and two animals developed pulmonary edema (with rales and production of pink frothy sputum).

(d) In four animals the effect of pacing on left ventricular function, as assessed by pressure-function curves, was evaluated during acute and healing myocardial infarction. Left ventricular function curves were constructed by plotting left ventricular developed pressure (left ventricular systolic peak pressure minus left ventricular end-diastolic pressure) against left ventricular end-diastolic pressure during transient aortic occlusion with a balloon-tip catheter (18).

In each of these four conditions observations were made in the control state with the animal's own rhythm and rate and again after 5-15 min of a stable period of atrial pacing at a rate of approximately 180 beats $/ \mathrm{min}$. In two animals with acute myocardial infarction and in two animals with healing myocardial infarction the pacing was continued for a period of $90 \mathrm{~min}$ to test the effects of prolonged pacing.

TABLE I

Hemodynamic Effects of Pacing in the Control State and 1 hr after Acute Myocardial Infarction ( $n=8, M e a n \pm S E M)$

\begin{tabular}{|c|c|c|c|c|c|c|}
\hline \multirow[t]{2}{*}{ 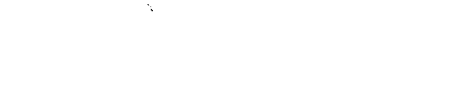 } & \multicolumn{3}{|c|}{ Control } & \multicolumn{3}{|c|}{ Acute myocardial infarction } \\
\hline & Prepacing & Pacing & $P$ & Prepacing & Pacing & $P$ \\
\hline Heart rate, beats/min & $88 \pm 5$ & $172 \pm 4$ & $<0.001$ & $110 \pm 2^{*}$ & $180 \pm 1$ & $<0.001$ \\
\hline Cardiac output, liters / $\min$ & $3.71 \pm 0.23$ & $4.08 \pm 0.28$ & NS & $3.30 \pm 0.15$ & $3.65 \pm 0.29$ & NS \\
\hline Aortic mean pressure, $m m ~ H g$ & $111 \pm 4$ & $123 \pm 3$ & $\mathrm{NS}$ & $123 \pm 6$ & $127 \pm 7$ & NS \\
\hline $\begin{array}{l}\text { Pulmonary artery mean pressure, } \\
m m \mathrm{Hg}\end{array}$ & $12 \pm 1$ & $14 \pm 1$ & NS & $17 \pm 2^{*}$ & $16 \pm 2$ & NS \\
\hline $\begin{array}{l}\text { Left ventricular end-diastolic } \\
\text { pressure, } m m \mathrm{Hg} \\
\text { Left atrial mean pressure, } \neq\end{array}$ & $6.2 \pm 1.0$ & $3.8 \pm 1.2$ & $<0.05$ & $18.8 \pm 2.9^{*}$ & $8.1 \pm 1.5$ & $<0.01$ \\
\hline $\begin{array}{l}m m H g \\
\text { Total peripheral resistance. }\end{array}$ & $8.6 \pm 1.0$ & $8.6 \pm 1.2$ & NS & $17.0 \pm 3.1^{*}$ & $12.2 \pm 1.2$ & $<0.05$ \\
\hline $\begin{array}{l}\text { dyne-sec- } \mathrm{cm}^{-5} \\
\text { Total pulmonary resistance, }\end{array}$ & $2439 \pm 185$ & $2473 \pm 116$ & NS & $3050 \pm 207$ & $2890 \pm 260$ & $\mathrm{xS}$ \\
\hline dyne-sec-cm-5 & $267 \pm 23$ & $274 \pm 29$ & NS & $453 \pm 50^{*}$ & $336 \pm 37$ & $<0.05$ \\
\hline
\end{tabular}

$* P<0.02$ compared to prepacing control.

$\ddagger$ Data from four animals. 
TABLE II

Hemodynamic Effects of Pacing in Healing Myocardial Infarction ( $n=8$, Mean $\pm S E M)$

\begin{tabular}{|c|c|c|c|}
\hline & Prepacing & Pacing & $P$ \\
\hline Heart rate, beats/min & $102 \pm 3$ & $180 \pm 1$ & $<0.01$ \\
\hline Cardiac output liters/min & $3.34 \pm 0.36$ & $4.59 \pm 0.63$ & $<0.05$ \\
\hline Aortic mean pressure, $m m \mathrm{Hg}$ & $120 \pm 4$ & $122 \pm 4$ & NS \\
\hline $\begin{array}{l}\text { Pulmonary artery mean pressure, } \\
\qquad m m ~ H g\end{array}$ & $18 \pm 2$ & $18 \pm 2$ & NS \\
\hline $\begin{array}{l}\text { Left ventricular end-diastolic } \\
\text { pressure, } m m \mathrm{Hg}\end{array}$ & $17.0 \pm 1.6$ & $9.5 \pm 0.6$ & $<0.01$ \\
\hline $\begin{array}{l}\text { Left atrial mean pressure, } \\
\qquad m m \mathrm{Hg}\end{array}$ & $10.2 \pm 0.9$ & $8.1 \pm 0.4$ & $<0.05$ \\
\hline $\begin{array}{l}\text { Total peripheral resistance, } \\
\text { dynes-sec- } \mathrm{cm}^{-5}\end{array}$ & $3085 \pm 423$ & $2381 \pm 390$ & $<0.05$ \\
\hline $\begin{array}{l}\text { Total pulmonary resistance, } \\
\text { dynes-sec-cm }\end{array}$ & $600 \pm 50$ & $524 \pm 62$ & $<0.05$ \\
\hline
\end{tabular}

* Data from four animals.

Instrumentation. Atrial pacing was carried out using a Grass model S4G stimulator (Grass Instrument Co., Quincy, Mass.). All recordings were made on a multichannel photographic recorder (Hewlett Packard Co., Waltham, Mass.) at paper speeds of $25-100 \mathrm{~mm} / \mathrm{sec}$. Pressures were measured using Statham P23Db and P23G transducers. The zero for pressure measurement was taken at mid-chest level. Left ventricular pressures were recorded at high and low gain simultaneously. For illustration the tracings were reproduced on a direct writer recorder (Sanborn 964; Sanborn Div., Hewlett-Packard Co.) from a magnetic tape. Cardiac output was determined by the indicator dilution technique using indocyanine green dye.

Statistical analysis. The data are presented as mean \pm SEM, and results were compared by means of the paired $t$ test (21).

\section{RESULTS}

\section{Pacing before and after myocardial infarction}

The data obtained from eight animals are summarized in Tables I and II.

Before myocardial infarction. In the control state, when the heart rate was increased from $88 \pm 5$ to 172 \pm 4 beats/min, left ventricular end-diastolic pressure decreased from 6 to $4 \mathrm{~mm} \mathrm{Hg}$. Cardiac output, aortic mean pressure, mean left atrial pressure, and total systemic and pulmonary resistances did not change significantly (Table I).

Acute myocardial infarction. $1 \mathrm{hr}$ after myocardial infarction there was a $25 \%$ increase in heart rate. Left ventricular failure was manifested by elevated left ventricular end-diastolic pressure and left atrial pressure in every instance. Cardiac output decreased $11 \%$, but the change was not significant. Pacing at a rate of 180 \pm 1 beats/min resulted in a decrease in left ventricular end-diastolic pressure from 19 to $8 \mathrm{~mm} \mathrm{Hg}$ and in left atrial pressure from 17 to $12 \mathrm{~mm} \mathrm{Hg}$. At the cessation of pacing the left ventricular end-diastolic pressure promptly returned to prepacing levels without any "overshoot" (Fig. 1). Overshoot is defined as an increase of left ventricular filling pressure above the level observed before pacing was initiated (13). In the two animals in which pacing was continued for a period of $90 \mathrm{~min}$ left ventricular end-diastolic and left atrial pressures decreased and remained stable for this time. Aortic mean pressure and cardiac output remained stable. Again no overshoot was observed when pacing was stopped.

Healing myocardial infarction. $1 \mathrm{wk}$ after acute myocardial infarction all animals had persistent elevation of left ventricular end-diastolic pressure. Atrial pacing at a rate of $180 \pm 1$ beats/min increased the cardiac output by $37 \%$. Left ventricular end-diastolic and left atrial pressures decreased in every animal (Table II). Total peripheral resistance decreased by $23 \%$ and total pulmonary resistance by $13 \%$. When pacing was stopped the pressures returned to prepacing levels without any overshoot (Fig. 2). In the two animals in which pacing was continued for $90 \mathrm{~min}$, the changes in left ventricular end-diastolic and left atrial pressure were found to be stable.

Pacing during acute myocardial infarction and beta adrenergic blockade (Table III)

In this group of six animals, $1 \mathrm{hr}$ after myocardial infarction the spontaneous heart rate increased by $21 \%$, and left ventricular end-diastolic pressure increased from 7 to $18 \mathrm{~mm} \mathrm{Hg}$. These changes were comparable with those occurring in the group of eight animals described previously (Table I). In addition, a $17 \%$ decrease in cardiac output was observed (Table III). Atrial pacing at a rate of $175 \pm 7$ beats/min significantly 
decreased the left ventricular end-diastolic and left atrial pressures, and also it significantly increased cardiac output. 15 min after cessation of pacing, when the hemodynamic parameters had returned to prepacing levels, propranolol was administered. Left ventricular failure worsened after beta blockade as evidenced by marked increases in left ventricular end-diastolic, left atrial, and pulmonary arterial pressures, despite a significant decrease in mean aortic pressures. Now the institution of atrial pacing at a rate of $176 \pm 5$ beats/ min decreased the left ventricular failure, and the hemodynamic parameters returned towards the preinfarction level.

A significant fall in left ventricular end-diastolic, left atrial, and pulmonary arterial pressures was observed and was accompanied by a $25 \%$ increase in cardiac output. A significant decrease in total peripheral and total pulmonary resistance was also noted. The increase in cardiac output and decrease in left ventricular filling pressure was noted in every animal.

Pacing in severe left ventricular failure of

healing anterior wall infarction and

circumflex coronary artery constriction

In two dogs which had undergone left anterior descending coronary artery occlusion $1 \mathrm{wk}$ previously, the circumflex coronary artery was partially occluded. This resulted in severe left ventricular failure, which was stable over a period of hours. Both animals developed pulmonary edema. The spontaneous heart rates at the time of pulmonary edema were 100 and 115 beats $/ \mathrm{min}$, respectively. With pacing at a rate of 180 beats/min left ventricular end-diastolic pressure decreased from 34 to $17 \mathrm{~mm} \mathrm{Hg}$ and 32 to $26 \mathrm{~mm} \mathrm{Hg}$, and cardiac output increased from 3.2 to 3.7 liters/min and 2.0 to 2.7 liters/min, respectively. Crepitation in the lungs disappeared in both dogs.

\section{Left ventricular function in myocardial infarction and pacing}

In four animals left ventricular pressure function curves were constructed at spontaneous rates and with heart rate controlled by atrial pacing both in the control state and after acute or healing myocardial infarction. Before myocardial infarction, atrial pacing did not significantly alter the left ventricular function curves; however, in three of the four animals after acute or healing myocardial infarction (MI), a shift of the ventricular function curves to the left was observed (Fig. 3). The improvement was noted both in the ascending limb and peak (maximal strength) of the

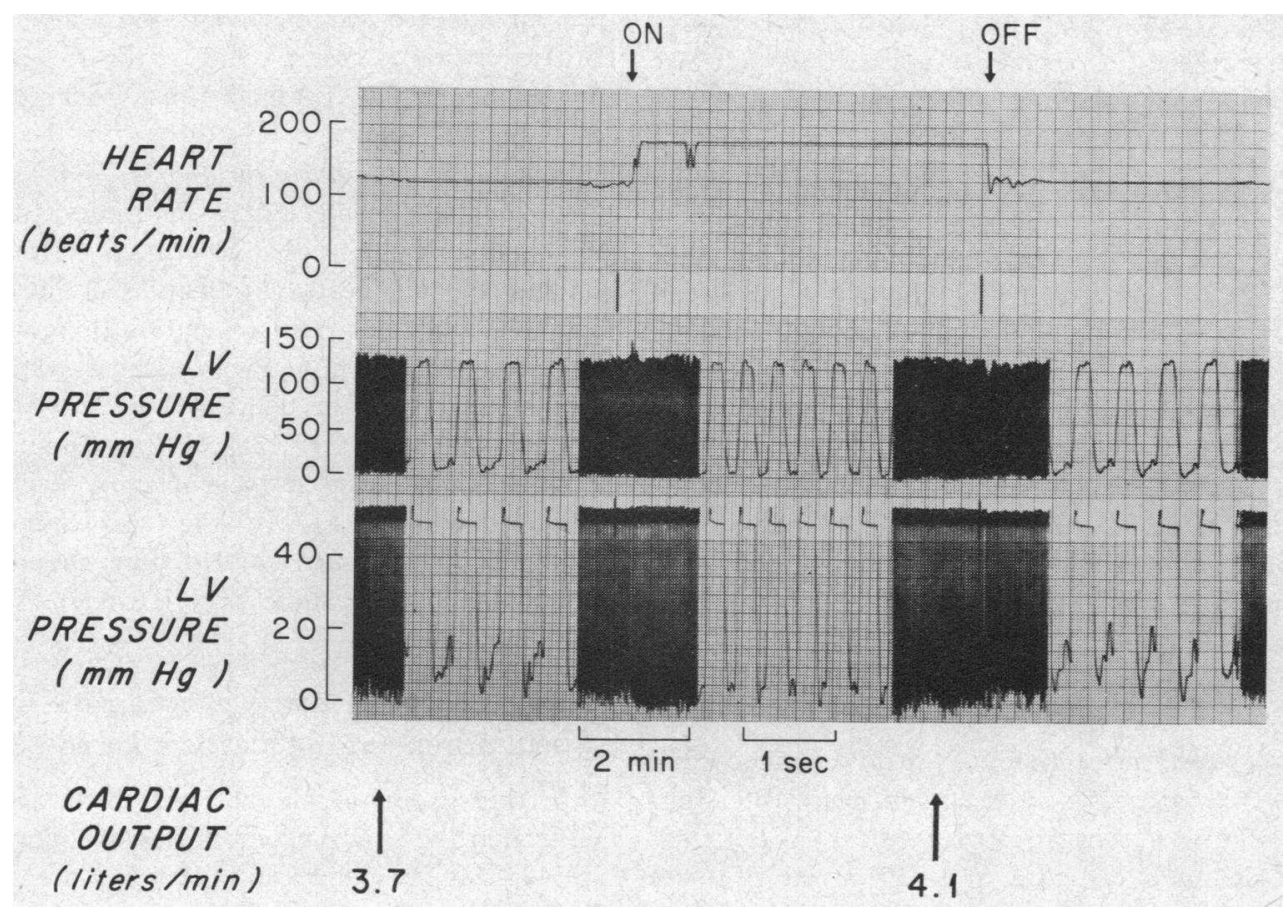

FIGURE 1 Effect of atrial pacing at 180 beats/min upon left ventricular pressures and cardiac cutput. The animal was studied $1 \mathrm{hr}$ after acute myocardial infarction. With onset of pacing left ventricular end-diastolic pressure declined from 15 to $5 \mathrm{~mm} \mathrm{Hg}$, and with cessation of pacing there was a prompt return to base line. In this example cardiac output increased from 3.7 to 4.1 liters/min with pacing. 


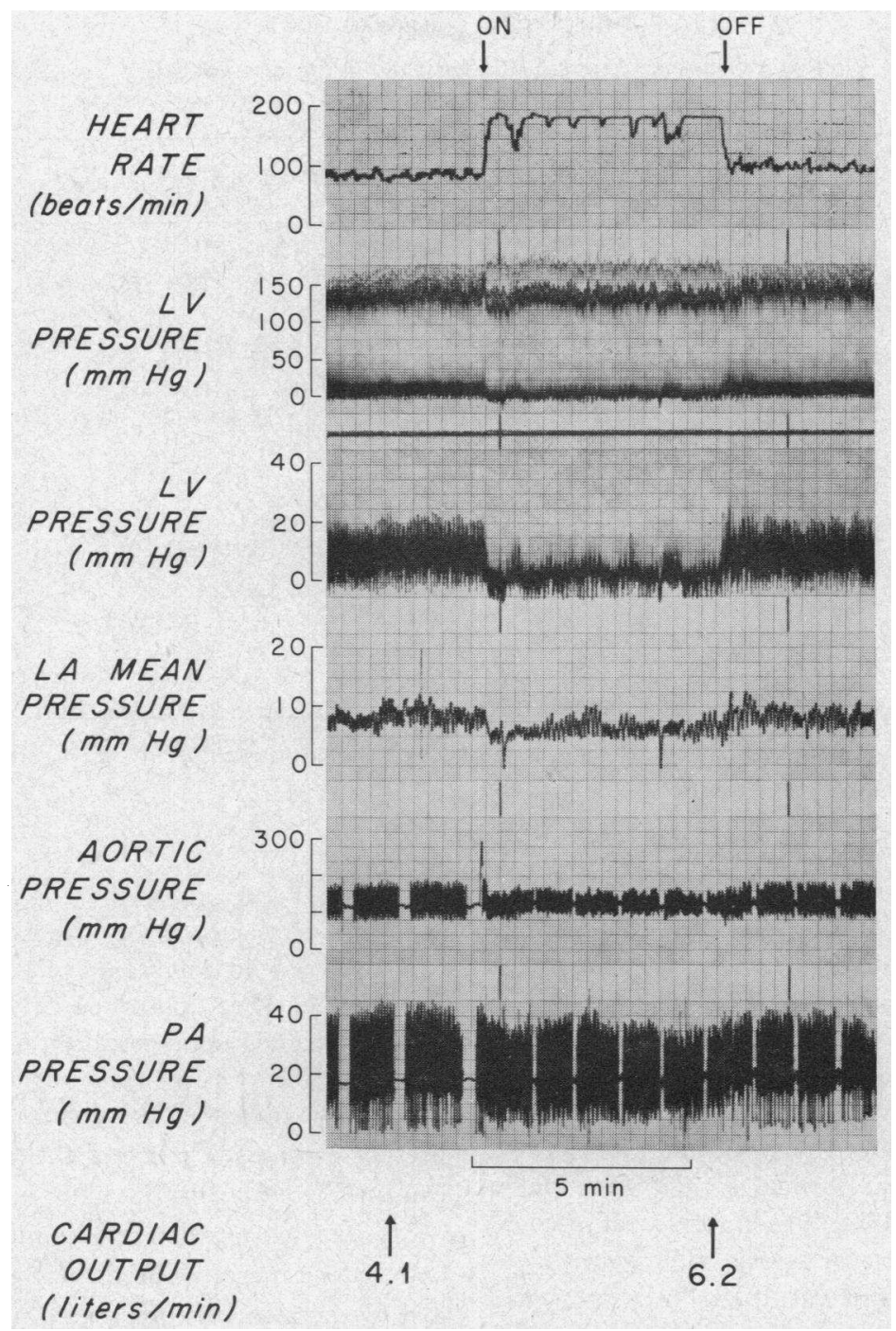

FIGURE 2 Effect of atrial pacing at 185 beats/min upon hemodynamic measurements. The animal was studied $1 \mathrm{wk}$ after acute myocardial infarction. Pacing caused a decline in left ventricular end-diastolic and left atrial mean pressures and an increase in cardiac output, with no change in aortic or pulmonary arterial pressures. Pressures returned to base line with cessation of pacing. The tracings of phasic aortic and pulmonary arterial pressure are interrupted intermittently by recordings of mean pressure.

function curve. Thus during atrial pacing a higher left ventricular pressure could be developed at a given left ventricular end-diastolic pressure (Fig. 3). The one animal in which no improvement in left ventricular function was seen with atrial pacing merits further comments. In this animal acute myocardial infarction resulted in a marked depression of cardiac function. In addition to a markedly depressed left ventricular function curve, cardiac output decreased by $45 \%$ and left ventricular systolic pressure fell by $20 \%$. This animal died of ventricular fibrillation $2 \mathrm{hr}$ after myocardial infarction. A marked decrease in both cardiac output and aortic pressure is unusual in this model of coronary insufficiency in awake dogs, in contrast to anesthetized dogs, where this is often seen.

\section{DISCUSSION}

Despite the clear evidence that increased frequency of contraction augments contractile force in isolated cardiac muscle, isolated ventricle $(1,2)$, and controlled intact 
TABLE III

Hemodynamic Effects of Pacing in Severe Left Ventricular Failure of Acute Myocardial Infarction Enhanced with Propranolol $(n=6$, Mean $\pm S E M)$

\begin{tabular}{|c|c|c|c|c|c|c|}
\hline & Control & Pacing & $\begin{array}{l}\text { Acute myocardial } \\
\text { infarction }\end{array}$ & Pacing & Propranolol & Pacing \\
\hline Heart rate, beats/min & $90 \pm 9$ & $155 \pm 8^{*}$ & $109 \pm 7^{*}$ & $175 \pm 7 \ddagger$ & $119 \pm 3$ & $176 \pm 5^{*}+\S$ \\
\hline Cardiac output, liters/min & $3.85 \pm 0.44$ & $3.76 \pm 0.19$ & $3.18 \pm 0.31^{*}$ & $3.56 \pm 0.31 \ddagger$ & $3.11 \pm 0.43$ & $3.91 \pm 0.44 \ddagger \S$ \\
\hline $\begin{array}{l}\text { Aortic mean pressure, } \\
m m \mathrm{Hg} \\
\text { Pulmonary artery mean }\end{array}$ & $114 \pm 5$ & $117 \pm 4$ & $127 \pm 5^{*}$ & $127 \pm 5$ & $117 \pm 7 \ddagger$ & $118 \pm 8 \ddagger$ \\
\hline $\begin{array}{l}\text { Pulmonary artery mean } \\
\text { pressure, } m m \mathrm{Hg} \\
\text { Left ventricular end- }\end{array}$ & $14 \pm 2$ & $14 \pm 1$ & $22 \pm 2^{*}$ & $20 \pm 2$ & $27 \pm 2 \ddagger$ & $23 \pm 2 * \S$ \\
\hline $\begin{array}{l}\text { diastolic pressure, } \mathrm{mm} \mathrm{Hg} \\
\text { Left atrial mean }\end{array}$ & $7.1 \pm 2.1$ & $5.3 \pm 1.7$ & $18.2 \pm 2.8^{*}$ & $8.1 \pm 1.5 \ddagger$ & $23.3 \pm 2.2 \ddagger$ & $12.2 \pm 1.4^{*} \S$ \\
\hline $\begin{array}{l}\text { pressure, } \| m m ~ H g \\
\text { Total peripheral resistance, }\end{array}$ & $7.6 \pm 1.7$ & $7.1 \pm 2.2$ & $14.6 \pm 2.4^{*}$ & $10.5 \pm 1.5 \ddagger$ & $23.1 \pm 2.4 \ddagger$ & $14.5 \pm 2.3^{*} \S$ \\
\hline $\begin{array}{l}\text { dyne-sec- } \mathrm{cm}^{-6} \\
\text { Total pulmonary resistance, }\end{array}$ & $2556 \pm 380$ & $2528 \pm 59$ & $3381 \pm 474^{*}$ & $2942 \pm 260$ & $3237 \pm 435$ & $2625 \pm 4.4 \ddagger \S$ \\
\hline dyne-sec- $\mathrm{cm}^{-5}$ & $326 \pm 69$ & $297 \pm 32$ & $559 \pm 58^{*}$ & $460 \pm 63 \ddagger$ & $768 \pm 120$ & $517 \pm 93 \S$ \\
\hline
\end{tabular}

* Significantly different from the control, $P<0.05$ (not analyzed for pacing or propranolol after infarction).

$\ddagger$ Significantly different from acute myocardial infarction, $P<0.05$.

\$ Significantly different from propranolol, $P<0.05$.

|| Left atrial pressures were recorded in five animals.

canine ventricle on bypass (5), improved performance of the left ventricle is not uniformly demonstrated in the intact conscious state in normal humans and in canine studies (8-10). In the present study, the effect of atrial pacing at 180 beats/min was evaluated in a canine model of myocardial infarction with depressed left ventricular function. This level of induced tachycardia was selected because of the evidence that optimal cardiac function in the presence of elevated filling pressures is achieved at this rate (6). It was found that $1 \mathrm{hr}$ after acute myocardial infarction, left ventricular filling pressure could be considerably decreased by pacing (Tables I and III). Furthermore, improved left ventricular function could be demonstrated from left ventricular function curves (Fig. 3 ). In the healing phase of myocardial infarction 1 wk later, induced tachycardia again relieved left ventricular failure and improved the left ventricular function curve. At this time, in addition to a decrease in left ventricular end-diastolic pressure, there was a $37 \%$ increase in cardiac output whereas total peripheral and pulmonary resistances decreased (Table II). Improvement of cardiac function by pacing could also be demonstrated in enhanced heart failure due to double-vessel coronary ischemia and in ventricles depressed by beta blockade (Table III). The latter suggests that the improved cardiac function with pacing in acute myocardial infarction is not catecholamine-mediated (4). After the pacing was stopped, even when prolonged up to $90 \mathrm{~min}$, the left ventricular end-diastolic pressure returned to pre- pacing levels, without any overshoot (Figs. 1 and 2). A transient rise in left ventricular end-diastolic pressure, however, has been observed in patients with angina induced by pacing upon cessation of stimulation, suggesting that rapid heart rates may under some conditions cause temporary ischemia. Absence of such changes in the present canine study favors the view that pacing did not cause ischemic injury in addition to that already present.

Myocardial oxygen consumption would be increased both by the increased frequency of contraction $(2,8,22)$ and by the associated increased inotropic state. However, oxygen consumption would be decreased by the reduction in left ventricular end-diastolic pressure and presumably volume, which could cause a decreased wall stress (23). Factors which limit the reduction of ventricular volume in the presence of infarction do, however, exist. With elevated left ventricular end-diastolic pressure, the ventricle is operating upon the steep portion of the diastolic compliance curve, so that a large decrease in end-diastolic pressure (Tables I-III) may be accompanied by only a small decrease in end-diastolic volume. In healing infarction, reduced over-all left ventricular compliance has been demonstrated (24), so that this effect would be accentuated. Furthermore, a dilated ventricle will increase wall thickness proportionately less than a smaller ventricle with a given reduction in volume, which may minimize reductions in wall stress. Whether an increase or decrease in oxygen consumption of the left ventricle 


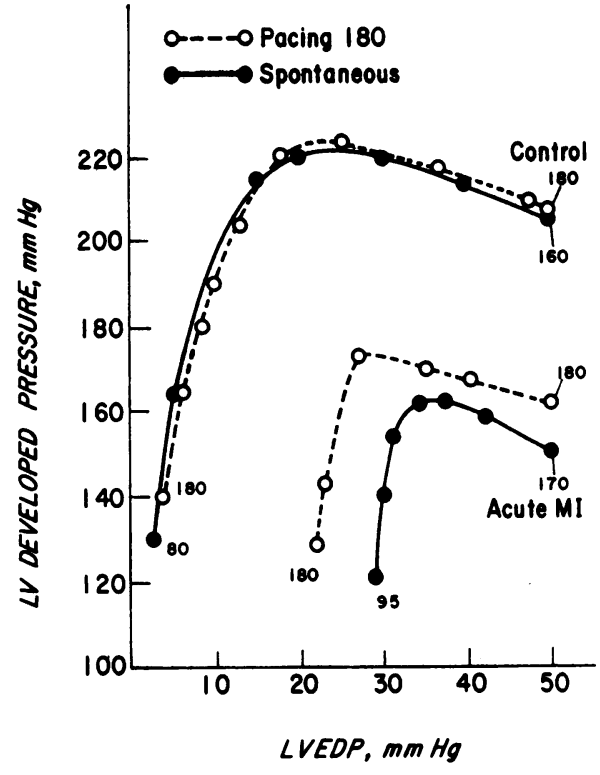

Figure 3 Ventricular function curves obtained in one animal before (upper curves) and $1 \mathrm{hr}$ after (lower curves) acute myocardial infarction. Closed circles show curves obtained with spontaneous ventricular rate, which increased from 80 to 160 beats/min during aortic obstruction before myocardial infarction, and from 95 to 170 beats/min during aortic obstruction after myocardial infarction. Open circles show curves obtained during aortic obstruction when rate was held constant at 180 beats/min by pacing. Note that identical function curves were obtained with and without pacing before myocardial infarction. After myocardial infarction the function curve obtained in the absence of pacing was depressed downward and to the right. However, pacing at 180 beats $/ \mathrm{min}$ led to improvement in this depressed function curve.

occurs with pacing would depend upon which of these various factors predominate.

These considerations regarding the over-all oxygen requirement in the infarcted left ventricle may have only an indirect bearing upon the behavior of the infarcted portion of the left ventricle. In areas which are totally ischemic and irreversibly injured, presumably hemodynamic factors which influence the oxygen consumption of the remainder of the ventricle are of little or no consequence. However, in border zones of marginal ischemia around the infarct, increases in heart rate might increase oxygen requirement and thereby increase the degree of injury to these tissues. Indeed it has been suggested that induced tachycardia can increase the area of the epicardial zone of injury determined by electrocardiography in experimental infarction (25). The results of the present study suggest, however, that these effects, if present, are small and of little or no hemodynamic consequence in the experimentally infarcted, in- tact canine ventricle. The implication of this finding is that the so-called marginal zone of ischemia is small in mass or functional importance. These results agree with studies of the effects of hyperbaric oxygenation upon acute cardiac failure in canine infarction, in which no improvement in left ventricular failure is observed (26).

Also of interest is the difference between the response to pacing in acute and healing infarction. A decrease of left ventricular end-diastolic pressure was noted in both states (Tables I and II), but a consistent increase in output was observed only in healing infarction (Table II). Increased responsiveness to inotropic drugs in healing as compared to acute infarction has also been observed (27). Immediately after infarction the left ventricular response to a pressure or volume load is depressed. In addition to loss of mass of contracting myocardium, sequestration of blood in the aneurysmal bulge is an important factor in this depression of left ventricular function. The limited benefit from inotropic interventions observed in the acute stage of infarction may be due to dissipation of energy into the aneurysmal bulge, despite increased contractility of the remaining healthy myocardium $(27,28)$. However, in the healing phase of myocardial infarction, when the infarcted zone becomes stiff and inelastic (24), increased contractility may be translated into increased stroke volume. This increase in cardiac output will not significantly increase oxygen requirement, since volume work alone causes only minor alterations in myocardial oxygen consumption (2).

In the present study increased frequency of contraction was achieved by atrial pacing, and effects of ventricular pacing were not explored. In some studies, ventricular pacing has been shown to induce asynchronous contraction of the ventricle (29), which will possibly limit its value. Paired pacing is known to increase myocardial contractility, but in myocardial infarction it is attendant with high risk of ventricular fibrillation (30).

In humans with coronary artery disease without left ventricular failure it has been shown that angina pectoris can often be precipitated at higher heart rates $(13,14)$. However, in some patients angina cannot be brought about with pacing (14). Heart rates required to precipitate angina with pacing are much higher than those associated with exercise (14). On the contrary, in patients with acute myocardial infarction, recurrences or exacerbation of chest pain are seldom caused by spontaneously occurring or induced tachycardias, either due to tachyarrhythmias, to injections of atropine or isoproterenol. or to rapid pacing to "overdrive" ectopic arrhythmias. ${ }^{1}$ If occurrence of chest pain can be equated with ischemia, these findings would suggest that, in the presence of

\footnotetext{
${ }^{1}$ Hood, W. B., Jr. Unreported observations.
} 
discrete areas of myocardial necrosis (i.e. acute myocardial infarction) as opposed to areas of poorly perfused but viable muscle (i.e. angina without infarction), induced tachycardia may not exert a deleterious effect.

The results of the present study in experimental canine myocardial infarction are in agreement with this clinical observation. Rapid pacing not only fails to exacerbate failure due to myocardial infarction in dogs, but actually improves left ventricular function. This finding need not lead to the conclusion that rapid pacing would be beneficial in all patients with left ventricular failure due to myocardial infarction; there are undoubtedly differences in adequacy of collaterals, and perhaps in the size of the "marginal zone of ischemia" around an infarct in the chronically diseased human heart, as compared with the normal but infarcted canine heart. However these results in dogs may provide some basis for cautious short-term trials of rapid atrial pacing for left ventricular failure or pulmonary edema in patients.

\section{ACKNOWLEDGMENTS}

We are grateful to Dr. Walter H. Abelmann for his helpful suggestions. The technical assistance of Richard Wagner, B.E.E., C. Thompson Jones, David P. Rhodes, Miss Mary T. Collins, and Mrs. Deborah T. Powell is fully acknowledged. We are grateful to Hynson, Westcott \& Dunning, Baltimore, Md., for the indocyanine green and to Ayerst Laboratories, New York, for the propranolol used in these studies.

This work was supported by Grants PH43-68-684, HE 5244, HE 10539, SF 57-111, and AM 10517 from the National Institutes of Health, and by the Ernest W. Lawson Grant, Northeast Chapter, Massachusetts Heart Association.

\section{REFERENCES}

1. Rosenblueth, A., J. Alanis, R. Rubio, and E. Lopez. 1959. The two staircase phenomena. Arch. Int. Physiol. Biochem. 67: 374.

2. Monroe, R. G., and G. N. French. 1961. Left ventricular pressure-volume relationships and myocardial oxygen consumption in the isolated heart. Circ. Res. 9: 362.

3. Abbott, B. C., and W. F. H. M. Mommaerts. 1959. A study of inotropic mechanisms in the papillary muscle preparation. J. Gen. Physiol. 42: 533.

4. Blinks, J. R., and J. Koch-Weser. 1961. Analysis of the effects of changes in rate and rhythm upon myocardial contractility. J. Pharmacol. Exp. Ther. 134: 373.

5. Covell, J. W., J. Ross, Jr., R. Taylor, E. H. Sonnenblick, and E. Braunwald. 1967. Effects of increasing frequency of contraction on the force velocity relation of left ventricle. Cardiovasc. Res. 1: 2.

6. Sugimoto, T., K. Sagawa, and A. C. Guyton. 1966. Effect of tachycardia on cardiac output during normal and increased venous return. Amer. J. Physiol. 211: 288.

7. Bristow, J. D., R. E. Ferguson, F. Mintz, and E. Rapaport. 1963. The influence of heart rate on left ventricular volume in dogs. J. Clin. Invest. 42: 649.
8. Berglund, E., H. G. Borst, F. Duff, and G. L. Schreiner. 1958. Effect of heart rate on cardiac work, myocardial oxygen consumption and coronary blood flow in the dog. Acta Physiol. Scand. 42: 185.

9. Pitt, B., and D. E. Gregg. 1968. Coronary hemodynamic effects of increasing ventricular rate in the unanesthetized dog. Circ. Res. 22: 753.

10. Samet, P., C. Castillo, and W. H. Bernstein. 1966. Hemodynamic consequences of atrial and ventricular pacing in subjects with normal hearts. Amer. J. Cardiol. 18: 522 .

11. Lassers, B. W., J. L. Anderton, M. George, A. L. Muir, and D. G. Julian. 1968. Hemodynamic effects of artificial pacing in complete heart block complicating acute myocardial infarction. Circulation. 38: 308.

12. Sowton, E. 1964. Haemodynamic studies in patients with artificial pacemakers. Brit. Heart J. 26: 737.

13. Parker, J. O., J. R. Ledwich, R. O. West, and R. B. Case. 1969. Reversible cardiac failure during angina pectoris: Hemodynamic effects of atrial pacing in coronary artery disease. Circulation. 39: 745.

14. O’Brien, K. P., L. M. Higgs, D. L. Glancy, and S. E. Epstein. 1969. Hemodynamic accompaniments of angina: A comparison during angina induced by exercise and by atrial pacing. Circulation. 39: 735.

15. Joison, J., R. Kumar, W. B. Hood, Jr., and J. C. Norman. 1969. An implantable system for producing left ventricular failure for circulatory-assist device evaluation. Trans. Amer. Soc. Artif. Intern. Organs. 15: 417.

16. Hood, W. B., Jr., J. Joison, R. Kumar, I. Katayama, R. S. Neiman, and J. C. Norman. 1970. Experimental myocardial infarction. I. Production of left ventricular failure by gradual coronary occlusion in intact conscious dogs. Cardiovasc. Res. 4: 73 .

17. Hood, W. B., Jr., R. Kumar, J. Joison, and J. C. Norman. 1970. Experimental myocardial infarction. V. Reaction to impaired circumflex flow in the presence of established anterior myocardial infarction in intact conscious dogs. Amer. J. Cardiol. 26: 355.

18. Kumar, R., W. B. Hood, Jr., J. Joison, J. C. Norman, and W. H. Abelmann. 1970. Experimental myocardial infarction. II. Acute depression and subsequent recovery of left ventricular function: serial measurements in intact conscious dogs. J. Clin. Invest. 49: 55.

19. Goodyer, A. V. N., M. J. Goodkind, and A. B. Landry. 1962. Ventricular response to a pressure load: Left ventricular function curved in intact animal. Circ. Res. 10: 885 .

20. Goodyer, A. V. N., M. J. Goodkind, and E. J. Stanley. 1964. The effects of abnormal concentrations of the serum electrolytes on left ventricular function in the intact animal. Amer. Heart J. 67: 779.

21. Snedecor, G. W. 1956. Statistical Methods applied to experiments in agriculture and biology. The Iowa State College Press, Ames, Iowa. 5th edition. 49.

22. Laurent, D., C. Bolene-Williams, F. L. Williams, and L. N. Katz. 1956. Effects of heart rate on coronary flow and cardiac oxygen consumption. Amer. J. Physiol. 185: 355 .

23. Graham, T. P., Jr., J. W. Covell, E. H. Sonnenblick, J. Ross, Jr., and E. Braunwald. 1968. Control of myocardial oxygen consumption: relative influence of contractile state and tension development. J. Clin. Invest. 47: 375 . 
24. Hood, W. B., Jr., J. A. Bianco, R. Kumar, and R. B. Whiting. 1970. Experimental myocardial infarction. IV. Reduction of left ventricular compliance in the healing phase. J. Clin. Invest. 49: 1316.

25. Braunwald, E., J. W. Covell, P. R. Maroko, and J. Ross, Jr. 1969. Effects of drugs and of counterpulsation on myocardial oxygen consumption. Observation on the ischemic heart. Circulation. 40 (Suppl. IV) : 220.

26. Gilmour, D., W. B. Hood, Jr., R. Kumar, J. Joison, J. C. Norman, and W. H. Abelmann. 1970. Hyperbaric oxygenation in acute myocardial infarction in intact conscious dogs. Fed. Proc. 29: 586. (Abstr.)

27. Kumar, R., W. B. Hood, Jr., J. Joison, D. P. Gilmour, J. C. Norman, and W. H. Abelmann. 1970. Experimental myocardial infarction. VI. Efficacy and toxicity of digitalis in acute and healing phase in intact conscious dogs. J. Clin. Invest. 49: 358.

28. Puri, P. S., and R. J. Bing. 1968. Effect of drugs on myocardial contractility in the intact dog and in experimental myocardial infarction: Basis for their use in cardiogenic shock. Amer. J. Cardiol. 21: 886.

29. Ueda, H., K. Harumi, and K. Ueda. 1968. Cineangiocardiographic observations on the asynchronism of cardiac contraction during ventricular pacing. Jap. Heart J. 9: 295.

30. Rothfeld, E. L., and I. R. Zucker. 1969. Paired pacing after coronary artery ligation. Circulation. 40 (Suppl. 3): 174. 